\title{
O princípio da fraternidade na Constituição Federal Brasileira de 1988
}

\author{
The principle of fraternity in Brazilian Federal Constitution of 1988
}

\author{
SONILDE K. LAZZARIN ${ }^{\mathrm{a}}$
}

\begin{abstract}
RESUMO
O reconhecimento de igual dignidade a todas as pessoas está consubstanciado na Constituição Federal Brasileira, assim como o objetivo da construção de uma sociedade fraterna, plural e sem preconceitos. O presente artigo demonstra que o fundamento para a revitalização do princípio da fraternidade encontra-se evidenciado em vários dispositivos constitucionais e que a própria igualdade somente é possível através do reconhecimento do outro, sem implicar a anulação das diferenças, ao contrário, com a aceitação das diferenças para construção de um mundo propriamente humano, representando uma terceira fase evolutiva do constitucionalismo: do liberal para o social e do social para o fraternal.
\end{abstract}

Palavras-chave: Fraternidade. Constitucionalismo. Dignidade.

\begin{abstract}
The recognition of equal dignity to all people is embodied in the Brazilian Federal Constitution, as well as the goal of building a fraternal, pluralistic and unprejudiced society. This article demonstrates that the foundation for the revitalization of the principle of fraternity lies evidenced in several constitutional provisions and that equality itself is only possible through the recognition of the other, without implying the cancellation of differences, instead, with the acceptance of differences to build a properly human world, representing a third evolutionary phase of constitutionalism: from the liberal to social and from the social to the fraternal.
\end{abstract}

Keywords: Fraternity. Constitutionalism. Dignity.

\section{INTRODUÇÃO}

$\mathrm{Na}$ atual conjuntura econômica verifica-se a falta de preocupação com o homem, com a sua dignidade. Importa referir que há um núcleo essencial dos direitos sociais que se encontra diretamente conectado ao princípio da dignidade e que é indispensável para uma vida digna e sobre os quais deve haver a proteção contra o retrocesso. Assim, para frear a crescente precarização dos direitos na complexa sociedade contemporânea, a dignidade humana tem que figurar em primeiro plano, o que dependerá de uma transformação da sociedade, implicando em uma alteração simultânea de todos os códigos pelos quais a sociedade é guiada, enfim, uma revolução mental, configurando um verdadeiro desafio ético.
O Brasil enfrenta graves problemas que afetam a dignidade humana, como a exploração de mão de obra em condições análogas às de escravos e a exploração do trabalho infantil. Para amenizar e erradicar essas chagas sociais não basta a mudança legislativa, é preciso mudar o paradigma social. Para tanto, traz-se à luz o princípio da fraternidade, não apenas como uma proposição ideal, mas como princípio ativo, como norteador do comportamento humano, pois enquanto a liberdade e igualdade conheceram uma evolução que as elevou a autênticas categorias políticas, capazes de se manifestarem como princípios constitucionais e também como ideias-força de movimentos políticos, a fraternidade viveu um percurso de um rio subterrâneo, mantendo-se o pensamento democrático a respeito da fraternidade em silêncio.

\footnotetext{
a Advogada Trabalhista e Previdenciária. Especialista, Mestre e Doutora em Direito pela Pontifícia Universidade Católica do Rio Grande do Sul/PUCRS. Professora de Direito do Trabalho e Direito Previdenciário da Universidade Federal do Rio Grande do Sul/UFRGS e da PUCRS. Professora convidada dos cursos de Pós-Graduação da PUCRS, UNIVATES, UNIRITTER e FEEVALE. Pesquisadora do Núcleo de Pesquisas CNPq/PUCRS Estado Processo e Sindicalismo.<sonilde@lazzarinadvogados.com.br>.
} 
A fraternidade pressupõe que a minha liberdade não se possa realizar sem a liberdade do outro, é considerada um princípio que está na origem de um comportamento relacional e, exatamente por isso, além de ser um princípio ao lado da liberdade e da igualdade, aparece como aquele que é capaz de tornar esses princípios efetivos.

A Constituição Federal de 1988 resgatou o princípio da fraternidade, na medida em que fez constar do Preâmbulo, o compromisso com uma sociedade fraterna, pluralista e sem preconceitos. Pode-se dizer que o constitucionalismo moderno conheceu duas fases, a primeira, fundada no liberalismo europeu, com destaque para o valor liberdade; a segunda, caracterizada pela social democracia, pelo constitucionalismo social, com ênfase no valor igualdade. A fraternidade seria uma terceira fase na evolução do constitucionalismo, do liberal para o social e do social para o fraternal.

\section{O PRINCÍPIO DA DIGNIDADE DA PESSOA HUMANA}

O princípio da dignidade impõe limites à atuação estatal, além disso, o Estado deverá ter como meta permanente proteção, promoção e realização concreta de uma vida com dignidade para todos. Significa dizer que o Estado tem a obrigação de promover as condições que viabilizam e removem toda sorte de obstáculos que estejam a impedir as pessoas de viverem com dignidade. Assim, de acordo com Sarlet, para além da vinculação do Estado quanto à dimensão positiva e negativa, todas as entidades privadas e os particulares encontram-se diretamente vinculados ao princípio da dignidade da pessoa humana, o que implica a existência de deveres de proteção e respeito também na esfera das relações entre particulares. Aduz o autor que pela natureza igualitária "por exprimir a ideia de solidariedade entre os membros da comunidade humana, o princípio da dignidade da pessoa vincula também no âmbito das relações entre os particulares"'.

A humanidade somente pode ser pensada se admitida à igualdade de todos os seres humanos. A igualdade se mostra universal na concretude, através do reconhecimento do outro, sem com isso implicar a anulação das diferenças, ao contrário, pressupõe a aceitação da diferença, e é essa aceitação que possibilita a construção de um mundo propriamente humano².

A vinculação dos particulares para a efetivação do princípio da dignidade assume grande importância em face do fenômeno da globalização, onde se verifica o aumento do poder exercido pelas grandes empresas nacionais e multinacionais e também aumento dos níveis de exclusão social.
No Brasil há dificuldade de se firmar a concepção moral do trabalho que perpasse sua dimensão meramente instrumental. Não se trata de uma ética do trabalho, mas uma ética de provedor que leva os membros da família a aceitarem a disciplina do trabalho. É assim, de acordo com Zaluar ${ }^{3}$, que o trabalhador pobre alcança a redenção moral e, portanto, a dignidade pessoal.

\section{LIBERDADE, IGUALDADE, FRATERNIDADE}

No preâmbulo da Constituição Federal brasileira, consta expressamente a liberdade, a igualdade e a referência a uma sociedade fraterna:

Nós, representantes do povo brasileiro, reunidos em Assembléia Nacional Constituinte para instituir um Estado Democrático, destinado a assegurar o exercício dos direitos sociais e individuais, a liberdade, a segurança, o bem-estar, o desenvolvimento, a igualdade e a justiça como valores supremos de uma sociedade fraterna, pluralista e sem preconceitos $[\ldots]^{4}$

Além dessa referência no preâmbulo, dispõe a referida Carta no artigo $3^{\circ}$, I, que constitui um dos objetivos fundamentais da República Federativa do Brasil, "construir uma sociedade livre, justa e solidária" e para tanto, deverá o Estado brasileiro, conforme incisos II, III e IV, do mesmo dispositivo, garantir o desenvolvimento nacional; erradicar a pobreza e a marginalização e reduzir as desigualdades sociais e regionais. Além disso, promover o bem de todos, sem preconceitos de origem, raça, sexo, cor, idade e quaisquer outras formas de discriminação. O artigo 170 dispõe que "a ordem econômica, fundada na valorização do trabalho humano e na livre iniciativa, tem por fim assegurar a todos existência digna, conforme os ditames da justiça social", tendo como princípios, além de outros, a redução das desigualdades regionais e sociais e a busca do pleno emprego ${ }^{5}$.

Portanto, através do princípio da solidariedade expresso na Carta Constitucional, é possível identificar a ideia de fraternidade. A solidariedade não é atributo específico ou restrito à ação do Estado. Trata-se aqui também da solidariedade, não pode ser reduzida ao preceito do não prejudicar os outros, mais do que isso, orienta a liberdade de modo mais vinculativo, no sentido de que o indivíduo deve fazer o bem ao outro, porque é também o seu bem.

Pode-se dizer que a liberdade econômica deve ser exercida de modo a atender os fins sociais. A Constituição Federal no artigo $5^{\circ}$ dispõe que todos são iguais perante a lei, sem distinção de qualquer natureza, garantindo a 
inviolabilidade do direito à vida, à liberdade, à igualdade, à segurança e à propriedade. Entretanto, no inciso XXIII diz que "a propriedade atenderá a sua função social"'. Não basta reconhecer a inviolabilidade do direito à propriedade, mas garantir constitucionalmente a sua função social.

Significa dizer que a orientação social constitucional das liberdades constitui o mesmo imperativo que deriva do princípio da subsidiariedade. Explica Pizzolato $^{7}$, embora se referindo à Itália, mas perfeitamente aplicável ao Brasil, que solidariedade e subsidiariedade estão entrelaçadas, na medida em que atribuem às articulações sociais intermediárias responsabilidades diretas na busca da finalidade solidária, reservando-se a ação direta do Estado um papel subsidiário, que respeita a missão intermediária de agrupamentos sociais, completando-a e, somente em caso de necessidade, substituindo-a. De acordo com essa ideia pode-se afirmar que o caminho da aplicação constitucional da subsidiariedade horizontal é também o caminho de uma aplicação constitucional possível da fraternidade.

De acordo com Sarlet ${ }^{8}$, os direitos fundamentais de primeira dimensão são os chamados direitos civis e políticos, englobam entre outros o direito à vida, à liberdade, à igualdade perante a lei, direito de participação política. Os direitos de segunda dimensão são denominados de direitos sociais ${ }^{9}$, econômicos e culturais, dentre os quais se reconhece os direitos dos trabalhadores, também se reportam ao indivíduo não podendo ser confundidos com os direitos coletivos e difusos de terceira dimensão. Os direitos da terceira dimensão comportam os direitos de solidariedade e fraternidade que são desprendidos da figura do indivíduo como titular, destina-se à proteção de grupos humanos, caracterizando-se como direitos de titularidade coletiva ou difusa. Dentre os mais citados direitos de terceira geração encontra-se o direito à paz, à autodeterminação dos povos, ao desenvolvimento, ao meio ambiente, à qualidade de vida e o direito de comunicação. Refere o autor que é compreensível a denominação usual de direitos de solidariedade ou de fraternidade devido "sua implicação universal ou, no mínimo, transindividual, e por exigirem esforços e responsabilidades em escala até mesmo mundial para sua efetivação".

Há também uma tendência de se reconhecer uma quarta dimensão, entretanto refere Sarlet, que ainda aguarda sua consagração na esfera do direito internacional e das normas constitucionais internas. Nessa dimensão se inserem o direito à informação, ao pluralismo, bem como a proteção a direitos decorrentes da evolução tecnológica, frente à globalização, manipulação genética, além de outros. Verifica-se que as diversas dimensões revelam que os direitos fundamentais se constituem em uma categoria aberta e mutável, ainda que observável certa permanência nesse campo, como o direito à vida e à liberdade. Ademais, observa Sarlet que alguns dos direitos clássicos de primeira e segunda dimensão estão na verdade, sendo revitalizados e ganhando importância e atualidade em face das novas modalidades de agressão aos valores tradicionais e incorporados ao patrimônio jurídico da humanidade, "nomeadamente da liberdade, da igualdade, da vida e da dignidade da pessoa humana" 10 .

Embora os direitos fundamentais se constituam em uma categoria aberta e mutável, não é possível o retrocesso social. De acordo com Canotilho, princípio da proibição do retrocesso social consiste em dizer que

o núcleo essencial dos direitos sociais já realizado e efetivado através de medidas legislativas deve considerar-se constitucionalmente garantido, sendo inconstitucionais quaisquer medidas estaduais que, sem a criação de outros esquemas alternativos ou compensatórios, se traduzam, na prática, numa anulação, revogação ou aniquilação pura e simples desse núcleo essencial. ${ }^{11}$

Sarlet refere que muitos direitos das três primeiras dimensões, embora já consagrados, encontram-se muito distante de uma implementação universal e satisfatória e que as novas e complexas situações e desafios reclamam um enfrentamento adequado, sem abandonar o Estado Democrático de Direito. Conclui-se que as três ou quatro dimensões, se assim for reconhecida mais uma dimensão, gravitam exatamente em torno da tríade: liberdade, igualdade, fraternidade ${ }^{12}$.

Sen ${ }^{13}$ ressalta a importância de considerar a liberdade individual um comportamento social, pois a expansão da liberdade é o principal fim e o principal meio do desenvolvimento. Para o autor "o desenvolvimento consiste na eliminação de privações de liberdade que limitam as escolhas e as oportunidades das pessoas de exercer ponderadamente sua condição de agente".

A universalidade da cidadania é de acordo com Bauman ${ }^{14}$, a condição preliminar de qualquer política de reconhecimento e a universalidade da humanidade é o horizonte pelo qual qualquer política de reconhecimento precisa orientar-se para ser significativa. Acrescenta o autor que a universalidade da humanidade não se opõe ao pluralismo das formas de vida humana, ao contrário, o pluralismo deve encorajar e viabilizar a discussão contínua sobre as condições compartilhadas do bem, a aceitação de valores comuns requer a ampliação das oportunidades e a maximização da liberdade individual. 
A eliminação de privações de liberdades substanciais é constitutiva do desenvolvimento. $\mathrm{O}$ autor ${ }^{15} \mathrm{faz}$ uma diferenciação entre liberdade formal e liberdade substancial. A liberdade formal indica os chamados direitos individuais, a liberdade que cada um tem de não ser tolhido no exercício de suas faculdades ou de seus direitos, exceto nos casos em que a lei o determina "são as liberdades sociais básicas cujo gozo o cidadão tem o 'direito' de ver assegurado por tribunais ou órgãos administrativos”. As liberdades substantivas incluem, entre outras, capacidades elementares como estar livre da fome crônica, da subnutrição, da morbidez evitável e da morte prematura, bem como as liberdades associadas a saber ler, escrever e conta, e ter participação política.

Refere Sarlet a efetiva dificuldade de proteção e implementação dos direitos fundamentais da segunda e da terceira dimensões, daí a necessidade de "alternativas não exclusivamente extraídas do ordenamento jurídico, além da revisão e adaptação dos mecanismos jurídicos tradicionais". De mais a mais, a evolução dos direitos fundamentais revela que cada vez mais "sua implementação em nível global depende de esforços integrados (por isso, direitos da solidariedade e fraternidade) dos Estados e dos povos" $"$.

$\mathrm{Na}$ Constituição da Itália fica evidenciado o personalismo como valor fundamental. Essa orientação caracteriza-se por ser contrária às concepções próprias do Estado totalitário, porque nesse, o indivíduo só encontra valor e dignidade no fato de ser parte de um organismo maior, que o transcende, a cuja prosperidade deve ele dedicar sua existência individual. Opõese também ao Estado liberal individualista, no qual predomina a ideia de que todos os homens nascem livres, iguais e independentes.

Refere Pizzolato ${ }^{17}$ que para caracterizar o personalismo constitucional não basta dizer que "já não devia ser o homem para o Estado, mas o Estado para o homem", pois essa simplificação expressa uma parte da verdade, pois não esclarece a diferença entre uma base individualista e outra personalista. Na primeira, percebese o sujeito como indivíduo, alguém que constrói para si uma identidade prescindindo dos outros e de um tecido de relações, a ideia de indivíduo como entidade originária, titular de direitos naturais precedentes à própria ideia de sociedade. Nessa ótica, a sociedade é fruto do livre ato de vontade, consequentemente, de um contrato estipulado entre indivíduos livres, independentes e iguais.

O personalismo tem uma base filosófica e antropológica bem definida, evidenciando-se o caráter social e político da pessoa, cuja identidade só se constrói na relação social com o diferente de si, no pertencimento histórico e no enraizamento cultural, num quadro de solidariedade que sustenta o próprio indivíduo e permite o seu desenvolvimento. Nessa perspectiva, de acordo com o mesmo autor ${ }^{18}$, a identidade humana interage com um ethos que precede o indivíduo e o socializa, significa dizer que o homem é um ser estruturalmente carente e aberto à relação com o diferente de si, sendo ao contrário da autonomia e independência, a interdependência estrutural que caracteriza o homem.

Desse modo, como é a fraqueza que identifica os homens entre si, não existe para a solidariedade o caminho do paternalismo, mas somente o da fraternidade, daí não correr o risco do personalismo cair no assistencialismo, exatamente porque não há separação entre uma categoria de fortes, que, de maneira paternalista, deve prestar socorro a uma categoria de fracos. O que há, é uma interdependência e uma fraternidade.

O princípio da fraternidade timidamente, mas presente no ordenamento jurídico pode ser aplicado ainda que por outras vias, mediante a efetivação do princípio da subsidiariedade ou ainda pela ponderação dos direitos, uma vez que não existe afirmação a priori de liberdade, mas o reconhecimento de um entrelaçamento dos direitos entre si e com as exigências sociais. Diante disso, a fraternidade vai atuar no ordenamento jurídico como solidariedade que nasce da ponderação entre as esferas de liberdade, que é confiada não à intervenção do Estado enquanto sujeito ativo da relação jurídica, mas a ação do Estado enquanto ordenamento jurídico ${ }^{19}$.

Diante dos processos mundiais de transformação política, com o surgimento da concepção política da democracia global com fundamento na liberdade, provoca um deslocamento da noção de igualdade, tendo-se em vista que nem sempre ocorrem iniciativas políticas destinadas a dar efetividade a uma verdadeira democracia global.

Como salienta Ferrara ${ }^{20}$, no plano político internacional, não existe um processo realmente democrático de formação da vontade política, fundado nos princípios de igual dignidade e de participação em todos os níveis; no plano socioeconômico e cultural, falta o reconhecimento dos direitos humanos em toda a sua amplitude e em todas as suas dimensões. Já no campo político global, enquanto a ideologia liberal é voltada para todos os atores sociais, o conceito de democracia ainda é seletivo, aplicado de modo preferencial e tendencialmente exclusivo à dimensão política interna dos Estados. Daí a necessidade de uma nova definição do conceito de democracia como processo que não se limita ao contexto nacional.

O processo da globalização produz efeitos devastadores para um grande número de pessoas, pois 
é guiado por poderes sem legitimidade democrática. Esse novo sistema de relações econômicas, sociais e culturais requer também uma nova ordem internacional. Para tanto, deveria ser um modelo cosmopolita de democracia, com base em princípios de direito válidos para as agregações internacionais regionais, como também para os contextos nacionais e locais. Dentro dessa perspectiva, a soberania deveria se tornar "uma função atuante nas várias dimensões políticas desse corpus jurídico-político de valor universal, no qual coexistiriam diversos níveis de poder, que cooperariam na configuração de uma governança cosmopolita" ${ }_{21}$, dentro da qual deveriam se abrir espaços de participação para o exercício de uma cidadania múltipla.

De acordo com Bonavides, o Estado social do constitucionalismo democrático da segunda metade do século XX afigura-se mais adequado a concretizar a universalidade dos valores das Declarações de Direitos fundamentais, porém há necessidade de uma mudança adaptativa aos respectivos fins. O Estado não pode objetivar a igualdade e liberdade apenas por meios intervencionistas e regulativos da Economia e da Sociedade. O Estado social deve estabelecer os pressupostos indispensáveis ao advento dos direitos de terceira geração,

onde a liberdade e a igualdade já não se contradizem com a veemência do passado; onde as diligencias do poder e do cidadão convergem, por inteiro, para trasladar ao campo da concretização direitos, princípios e valores que fazem o Homem se acercar da possibilidade de ser efetivamente livre, igualitário e fraterno. ${ }^{22}$

A Constituição Federal de 1988 resgatou o princípio da fraternidade, na medida em que fez constar do Preâmbulo, o compromisso com uma sociedade fraterna, pluralista e sem preconceitos ${ }^{23}$. Pode-se dizer que o constitucionalismo moderno conheceu duas fases, a primeira, fundada no liberalismo europeu, com destaque para o valor liberdade; a segunda, caracterizada pela social democracia, pelo constitucionalismo social, com ênfase no valor igualdade ${ }^{24}$. A fraternidade seria uma terceira fase na evolução do constitucionalismo, do liberal para o social e do social para o fraternal.

\section{A FRATERNIDADE COMO VALOR CONSTITUCIONAL}

É compreensível a dificuldade para incluir a fraternidade como categoria jurídica constitucional, tendo-se em vista que ela é, via de regra, compreendida como um agir espontâneo, destituído de coatividade, incompatível, portanto, com o direito. Porém, a fra- ternidade como princípio, inspira e norteia o conjunto de normas, além de apresentar também um importante critério interpretativo dessas mesmas normas ${ }^{25}$. Nesse sentido refere o Ministro Carlos Ayres Britto, do Supremo Tribunal Federal,

Os valores de berço constitucional são o hierárquico referencial de todos os outros valores de matriz infraconstitucional. Valores, estes últimos, que de alguma forma têm que se reconduzir aos primeiros, pena de invalidade. Tudo afunilando para esse valor-síntese em que se traduz a democracia de três vértices. ${ }^{26}$

No Brasil, de forma embrionária e contida, já se encontra nas decisões dos tribunais, a fraternidade como fundamento, como um valor constitucional. O Ministro Gilmar Mendes, à época Presidente do Supremo Tribunal Federal, ao decidir em Medida Cautelar em Arguição de Descumprimento de Preceito Fundamental - ADPF 186-2/DF, proposta pelo partido político Democratas (DEM), contra atos administrativos da Universidade de Brasília que instituíram o programa de cotas raciais para ingresso naquela universidade, além de outros fundamentos aplicou o princípio da fraternidade, dizendo que

No limiar deste século XXI, liberdade e igualdade devem ser (re)pensadas segundo o valor fundamental da fraternidade. Com isso quero dizer que a fraternidade pode constituir a chave por meio da qual podemos abrir várias portas para a solução dos principais problemas hoje vividos pela humanidade em tema de liberdade e igualdade. ${ }^{27}$

Mallet entende que as ações afirmativas tem amparo exatamente na ideia de igualdade substancial, pois o reequilíbrio de uma desigualdade fática somente é possível com uma desigualdade compensatória. Conclui que "não há, na adoção de medidas promocionais ou de favorecimento de grupos ou pessoas desfavorecidas, ofensa ao princípio da igualdade" 28 .

A tolerância nas sociedades multiculturais é o problema a ser enfrentado neste século em tema de liberdade e igualdade. De acordo com o Ministro

pensar a igualdade segundo o valor da fraternidade significa ter em mente as diferenças e as particularidades humanas em todos os seus aspectos. A tolerância em tema de igualdade, nesse sentido, impõe a igual consideração do outro em suas peculiaridades e idiossincrasias. Numa sociedade marcada pelo pluralismo, a igualdade só pode ser igualdade com igual respeito às diferenças. Enfim, no Estado democrático, a conjugação dos valores da igualdade e da fraternidade expressa 
uma normatividade constitucional no sentido de reconhecimento e proteção das minorias. [...] Se, por um lado, a clássica concepção liberal de igualdade como um valor meramente formal há muito foi superada, em vista do seu potencial de ser um meio de legitimação da manutenção de iniquidades, por outro o objetivo de se garantir uma efetiva igualdade material deve sempre levar em consideração a necessidade de se respeitar os demais valores constitucionais. [...] Assim, o mandamento constitucional de reconhecimento e proteção igual das diferenças impõe um tratamento desigual por parte da lei. O paradoxo da igualdade, portanto, suscita problemas dos mais complexos para o exame da constitucionalidade das ações afirmativas em sociedades plurais. ${ }^{29}$

No mesmo sentido, o Ministro Carlos Ayres Britto, ao fundamentar seu voto na Ação Direta de Inconstitucionalidade - ADI 3.128, que versava sobre a cobrança da contribuição previdenciária dos servidores inativos, refere que a solidariedade é na verdade a fraternidade, o terceiro valor, juntamente com a liberdade e a igualdade,

apercebi-me de que a solidariedade, como objetivo fundamental da República Federativa do Brasil, em verdade, é fraternidade, aquele terceiro valor fundante, ou inspirador da Revolução Francesa, componente, portanto - esse terceiro valor -, da tríade 'Liberté, Igualité, Fraternité', a significar apenas que precisamos de uma sociedade que evite as discriminações e promova as chamadas ações afirmativas ou políticas públicas afirmativas de integração civil e moral de segmentos historicamente discriminados, como o segmento das mulheres, dos deficientes físicos, dos idosos, dos negros, e assim avante. ${ }^{30}$

Na Justiça do Trabalho, no Tribunal Regional da 15를 Região, ao decidir um conflito relativo a uma grave doença decorrente do uso de amianto no ambiente de trabalho, condenou a empresa a indenizar o trabalhador. $\mathrm{Na}$ fundamentação do acórdão, a relatora referiu que o direito ao meio ambiente saudável faz parte dos direitos fundamentais de terceira geração, que abrangem os relacionados à solidariedade e à fraternidade:

A proteção do meio ambiente insere-se no quadro dos direitos fundamentais de terceira geração que abrangem os relacionados à solidariedade $\mathrm{e}$ fraternidade. Na esfera constitucional, o art. 225 consagra genericamente o direito ao 'meio ambiente ecologicamente equilibrado', inserindo dentre as obrigações do sistema único de saúde a de 'colaborar na proteção do meio ambiente, nele incluído o do trabalho' (art. 201, inciso VIII), medidas que visam à defesa da dignidade humana, entronizada a fundamento do Estado de Direito, nos termos do primeiro artigo, inciso III da CRFB/88. ${ }^{31}$

De acordo com a decisão, em um momento em que a poluição global revela a cada dia sua força destrutiva, tomando assento nas agendas das entidades transnacionais como a Organização das Nações Unidas, Organização Mundial da Saúde, Organização Internacional do Trabalho e outros órgãos não governamentais é indeclinável a função da Justiça do Trabalho de cumprir sua finalidade precípua, de resolver os conflitos decorrentes da prestação de serviços com auxílio da justiça restaurativa. Para tanto, é fundamental e necessária uma mudança urgente de rumo quanto às questões relacionadas ao meio ambiente de trabalho e para cumprir tão nobre desiderato

é necessário que os Tribunais comecem a emprestar (ou reconhecer) força normativa à Constituição, manuseando todo o ordenamento jurídico que the segue como um caminho seguro para garantir a eficácia plena de suas normas, jamais para esteri-

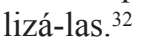

Em outro caso na esfera trabalhista, o princípio da fraternidade foi também aplicado, com base na Constituição Federal, para reintegrar um empregado dispensado logo após comunicar a empresa que estava com diagnóstico de neoplasia maligna, embora mantivesse a capacidade laborativa. Os desembargadores, ao contrário do juízo a quo, entenderam que a terminação do contrato de trabalho, logo após o conhecimento do resultado dos exames, caracteriza a dispensa discriminatória. Diz o relator em seu voto

Essa conduta viola, ainda, o preceito contido no art. $3^{\circ}$, I, da Carta Magna, atentando contra a edificação de uma sociedade solidária, cujo espírito deve ser perseguido em todos os setores sociais, por meio de ações, realizadas dentro da alçada de competências própria a cada um, que visem ao amparo daqueles que se encontram em posição de hipossuficiência nas relações às quais estão jungidos, incluindo-se aí as relações de emprego. Em outros dizeres, a sociedade solidária, objetivo fundamental da República, se apresenta como um instrumento de concreção da igualdade, pois, como ensina Hannah Arendt, os homens não nascem iguais, mas se tornam iguais, precisamente por passarem a integrar uma coletividade em que lhes sejam garantidos direitos iguais. Essa garantia, por sua vez, tem como finalidade maior a proteção da dignidade da pessoa humana. E o atingimento tanto 
dessa igualdade de direitos quanto da proteção da dignidade da pessoa humana passa necessariamente pela solidariedade social. ${ }^{33}$

No caso ficou caracterizada a quebra dos postulados constitucionais da dignidade da pessoa humana, da erradicação das formas de discriminação, da construção de uma sociedade solidária e da isonomia, conforme artigos $1^{\circ}$, III ${ }^{34}, 3^{\circ}$, I e IV ${ }^{35}$, e artigo $5^{\circ}$ da Constituição Federal $^{36}$, bem como da Convenção Internacional $\mathrm{n}^{\mathrm{o}}$ 111, da Organização Internacional do Trabalho ${ }^{37}$, ratificada pelo Brasil em 1965. Assim, a sociedade solidária como objetivo fundamental da República, se apresenta como um instrumento de concreção da igualdade.

\section{CONSIDERAÇÕES FINAIS}

Há uma compreensível dificuldade para incluir a fraternidade como categoria jurídica constitucional, tendo-se em vista que ela é, via de regra, compreendida como um agir espontâneo, destituído de coatividade, incompatível, portanto, com o direito. Porém, a fraternidade como princípio inspira e norteia o conjunto de normas, além de apresentar também um importante critério interpretativo dessas mesmas normas. Nesse sentido foi possível constatar que, embora de forma embrionária, a jurisprudência começa a caminhar nesse sentido.

Conclui-se que não apenas o Judiciário deve revitalizar o princípio da fraternidade, mas todas as esferas públicas, bem como as instituições privadas e cada um dos indivíduos. Para que isso ocorra são necessárias algumas redefinições, a conscientização de que a dignidade de uma pessoa faz parte da dignidade do outro, assim, é necessário reconhecer o outro como um irmão, como humano, portador de idêntica dignidade. Nesse contexto, o Estado também terá que redefinir seu papel na atual e complexa sociedade.

\section{REFERÊNCIAS}

BOMBASSARO, Luiz Carlos. Educação e formação humana: breves considerações sobre os aspectos filosóficos do humanismo no Brasil atual. In: DAL RI JÜNIOR, Arno; PAVIANI, Jayme (Orgs.). Humanismo latino no Brasil de hoje. Belo Horizonte: PUC Minas, 2001. 596p.

BONAVIDES, Paulo. Do estado liberal ao estado social. 10. ed. São Paulo: Malheiros, 2011. 230 p.

BRASIL. Constituição da República Federativa do Brasil de 1988. Disponível em: <https://www.planalto.gov.br/ccivil_03/ Constituicao/ConstituicaoCompilado.htm>. Acesso em: 20 jun. 2014.
BRASIL. Supremo Tribunal Federal. ADI 2.128. Disponível em: $<$ http://www.stf.jus. br/noticias/imprensa/ VotoBrittoInativos.pdf $>$. Acesso em: 20 jun. 2014.

BRASIL. Supremo Tribunal Federal. ADPF nº 186-2. Disponível em: <http://www. acoes.ufscar. br/admin/legislacao/arquivos/ arquivo13.pdf $>$. Acesso em: 20 jun. 2014.

BRASIL. Tribunal Regional do Trabalho da 15를 Região. Recurso Ordinário. 0163500-21.2005. 5.15.0102. 2 ${ }^{\mathrm{a}}$ Câmara (1 ${ }^{\mathrm{a}}$ Turma) do Tribunal Regional do Trabalho da 15a Região do Estado de São Paulo, Campinas,SP, Relatora Mariane Khayat, publicado em 06.02.2009. Disponível em: <http://www.trt15.jus.br/portal/portal/ trt15/home>. Acesso em: 10 ago. 2014.

BRASIL. Tribunal Regional do Trabalho da 15a Região. Recurso Ordinário. 0063000-58.2009. 5.15.0052, 4를 Câmara (2 ${ }^{-}$Turma) do Tribunal Regional do Trabalho da 15ª Região do Estado de São Paulo, Campinas, SP, Relator Luiz José Dezena da Silva, publicado em 13.07.2012. Disponível em: <http://www.trt15.jus.br/portal/ portal/trt15/ home>. Acesso em: 10 jul. 2014.

BRITTO, Carlos Ayres. O humanismo como categoria constitucional. Belo Horizonte: Fórum, 2010. 124p.

FERRARA, Pasquale. A fraternidade na teoria política internacional. In: BAGGIO, Antônio Maria.(Org.). O principio esquecido 1: a fraternidade na reflexão atual das ciências políticas. Tradução de Durval Cordas, Iolanda Gaspar e José Maria de Almeida. Vargem Grande Paulista, SP: Cidade Nova, 2008. 200p.

GORIA, Fausto. Fraternidade e Direito. In: CASO, Giovanni; CURY, Afife et al. (Orgs.). Direito e fraternidade. São Paulo: LTr, 2008. 192 p.

MACHADO, Carlos Augusto Alcântara. A fraternidade como categoria constitucional. In: SOUZA, Carlos Aurélio Mota; CAVALCANTI, Thaís Novaes (Coord.). Principios humanistas constitucionais: reflexões sofre o humanismo do século XXI. São Paulo: Letras Jurídicas, 2010. 406p.

MALLET, Estêvão. Igualdade, discriminação e Direito do Trabalho. Revista do Tribunal Superior do Trabalho, Brasília, v. 76, n. 3, jul.-set. 2010. p. 17-51.

ORGANIZAÇÃO INTERNACIONAL DO TRABALHO. Convenção Internacional $n^{-}$111, de 04 de junho de 1958, sobre Discriminação em Matéria de Emprego e Ocupação. Disponível em: <http://www.oitbrasil.org.br/node/472\# ftn1>. Acesso em: 10 jul. 2014

PIZZOLATO, Filippo. A fraternidade no ordenamento jurídico italiano. In: BAGGIO, Antônio Maria (Org.). O princípio esquecido 1: a fraternidade na reflexão atual das ciências políticas. Tradução de Durval Cordas, Iolanda Gaspar e José Maria de Almeida. Vargem Grande Paulista, SP: Cidade Nova, 2008. 200p.

SARLET, Ingo Wolfgang. A eficácia dos direitos fundamentais: uma teoria geral dos direitos fundamentais na perspectiva constitucional. 10. ed. Porto Alegre: Livraria do Advogado, 2010. $493 \mathrm{p}$.

SARLET, Ingo Wolfgang. Dignidade da pessoa humana e direitos fundamentais na Constituição Federal de 1988. 8. ed. Porto Alegre: Livraria do Advogado, 2010. 182p.

SEN, Amartya. Desenvolvimento como liberdade. Tradução de Laura Teixeira Motta. São Paulo: Companhia das Letras, 2000. $410 \mathrm{p}$.

SILVA, José Afonso. Curso de Direito Constitucional Positivo. 34. ed. São Paulo: Malheiros, 2011. 928 p.

ZALUAR, Alba. A máquina e a revolta: as organizações populares e o significado da pobreza. São Paulo: Brasiliense, 1985. $265 \mathrm{p}$. 


\section{NOTAS}

1 SARLET, Ingo Wolfgang. Dignidade da pessoa humana e direitos fundamentais na Constituição Federal de 1988. 8. ed. Porto Alegre: Livraria do Advogado, 2010, p. 127.

2 BOMBASSARO, Luiz Carlos. Educação e formação humana: breves considerações sobre os aspectos filosóficos do humanismo no Brasil atual. In: DAL RI JÙNIOR, Arno; PAVIANI, Jayme (Orgs.). Humanismo latino no Brasil de hoje. Belo Horizonte: PUC Minas, 2001, p. 72.

3 ZALUAR, Alba. A máquina e a revolta: as organizações populares e o significado da pobreza. São Paulo: Brasiliense, 1985, p. 121

4 BRASIL. Constituição da República Federativa do Brasil de 1988. Disponível em: <https://www.planalto gov.br/ccivil_03/Constituicao/ ConstituicaoCompilado.htm $>$. Acesso em: 20 jun. 2014 .

5 BRASIL. Constituição da República Federativa do Brasil de 1988. Disponível em: < https://www.planalto .gov.br/ccivil_03/Constituicao/ ConstituicaoCompilado.htm>. Acesso em: 20 jun. 2014.

6 BRASIL. Constituição da República Federativa do Brasil de 1988. Disponível em <https://www.planalto .gov.br/ccivil 03/Constituicao. htm>. Acesso em: 03 jan. 2014.

7 PIZZOLATO, Filippo. A fraternidade no ordenamento jurídico italiano. In: BAGGIO, Antônio Maria (Org.). O princípio esquecido 1: a fraternidade na reflexão atual das ciências políticas. Vargem Grande Paulista, SP: Cidade Nova, 2008, p. 121

8 SARLET, Ingo Wolfgang. A eficácia dos direitos fundamentais: uma teoria geral dos direitos fundamentais na perspectiva constitucional. 10. ed. Porto Alegre: Livraria do Advogado, 2010, p. 48.

9 Direito sociais conforme Silva, "são prestações positivas proporcionadas pelo Estado direta ou indiretamente, enunciadas em normas constitucionais, que possibilitam melhores condições de vida aos mais fracos, direitos que tendem a realizar a igualização de situações sociais desiguais". Significa dizer que são direitos que se relacionam ao direito de igualdade, na medida em que criam condições materiais mais propícias à igualdade real, o que, consequentemente, proporciona melhores condições para o exercício efetivo da liberdade. (SILVA, José Afonso. Curso de Direito Constitucional Positivo. 34. ed. São Paulo: Malheiros, 2011,. p. 286).

${ }^{10}$ SARLET, Ingo Wolfgang. A eficácia dos direitos fundamentais: uma teoria geral dos direitos fundamentais na perspectiva constitucional. 10. ed. Porto Alegre: Livraria do Advogado, 2010, p. 53.

${ }^{11}$ CANOTILHO, José Joaquim Gomes. Direito Constitucional e teoria da Constituição. 7. ed. Coimbra: Almedina, 2010, p. 340

12 SARLET, Ingo Wolfgang. A eficácia dos direitos fundamentais: uma teoria geral dos direitos fundamentais na perspectiva constitucional. 10 ed. Porto Alegre: Livraria do Advogado, 2010, p. 55.

13 SEN, Amartya. Desenvolvimento como liberdade. Tradução de Laura Teixeira Motta. São Paulo: Companhia das Letras, 2000, p. 10.

14 BAUMAN, Zygmunt. Comunidade: a busca por segurança no mundo atual. Tradução de Plínio Dentzien. Rio de Janeiro: Zahar, 2003, p. 126.

15 SEN, Amartya. Desenvolvimento como liberdade. Tradução de Laura Teixeira Motta. São Paulo: Companhia das Letras, 2000, p. 75-76.

${ }^{16}$ SARLET, Ingo Wolfgang. A eficácia dos direitos fundamentais: uma teoria geral dos direitos fundamentais na perspectiva constitucional. 10 . ed. Porto Alegre: Livraria do Advogado, 2010, p. 54

17 FERRARA, Pasquale. A fraternidade na teoria política internacional. In: BAGGIO, Antônio Maria.(Org.). O princípio esquecido 1: a fraternidade na reflexão atual das ciências políticas. Tradução de Durval Cordas, Iolanda Gaspar e José Maria de Almeida. Vargem Grande Paulista, SP: Cidade Nova, 2008, p. 117.

${ }_{18}$ PIZZOLATO, Filippo. A fraternidade no ordenamento jurídico italiano. In: BAGGIO, Antônio Maria (Org.). O princípio esquecido 1: a fraternidade na reflexão atual das ciências políticas. Tradução de Durval Cordas, Iolanda Gaspar e José Maria de Almeida. Vargem Grande Paulista, SP: Cidade Nova, 2008. p. 117.

${ }_{19}$ Ibidem, p. 124.

${ }^{20}$ FERRARA, Pasquale. A fraternidade na teoria política internacional. In: BAGGIO, Antônio Maria (Org.). O princípio esquecido 1: a fraternidade na reflexão atual das ciências políticas. Tradução de Durval Cordas, Iolanda Gaspar e José Maria de Almeida. Vargem Grande Paulista, SP: Cidade Nova, 2008, p. 163

${ }^{21}$ FERRARA, Pasquale. A fraternidade na teoria política internacional. In: BAGGIO, Antônio Maria (Org.). O princípio esquecido 1: a fraternidade na reflexão atual das cciências políticas. Tradução de Durval Cordas, Iolanda Gaspar e José Maria de Almeida. Vargem Grande Paulista, SP: Cidade Nova, 2008, p.117.

22 BONAVIDES, Paulo. Do Estado Liberal ao Estado Social. 10. ed. São Paulo: Malheiros, 2011, p. 33.

23 BRASIL. Constituição da República Federativa do Brasil de 1988. Disponível em: <https://www. planalto.gov.br/ccivil_03/Constituicao/ ConstituicaoCompilado.htm >. Acesso em: 03 ago. 2014.

${ }^{24}$ MACHADO, Carlos Augusto Alcântara. A fraternidade como categoria constitucional. In: SOUZA, Carlos Aurélio Mota; CAVALCANTI, Thaís Novaes (Coord.). Princípios Humanistas Constitucionais: reflexões sofre o humanismo do século XXI. São Paulo: Letras Jurídicas, 2010, p. 99.

${ }^{25}$ GORIA, Fausto. Fraternidade e direito:algumas reflexões. In: CASO, Giovanni et al. (Orgs.). Direito e fraternidade: ensaios/práticas forenses. Anais do Congresso Internacional "Relações no Direito: Qual Espaço para a Fraternidade?”. São Paulo: LTr, 2008, p. 27.

26 BRITTO, Carlos Ayres. O humanismo como categoria constitucional. Belo Horizonte: Fórum, 2010, p. 88.

27 BRASIL. Supremo Tribunal Federal. ADPF $n^{\circ}$ 186-2. Disponível em: $<$ http://www.acoes.ufscar. br/admin/legislacao/arquivos/arquivo13.pdf $>$ Acesso em: 15 maio 2014.

${ }^{28}$ MALLET, Estêvão. Igualdade, discriminação e Direito do Trabalho. Revista do Tribunal Superior do Trabalho, Brasília, v. 76, n. 3, jul.-set. 2010, p. 43.

${ }^{29}$ BRASIL. Supremo Tribunal Federal. ADPF $\mathrm{n}^{\circ}$ 186-2. Disponível em $<$ http://www.acoes.ufscar. br/admin/legislacao/arquivos/arquivo13.pdf > Acesso em: 18 jul. 2014.

${ }^{30}$ BRASIL. Supremo Tribunal Federal. ADI 2.128. Disponível em: $<$ http:// www.stf.jus.br/noticias/imprensa/ VotoBrittoInativos.pdf>. Acesso em: 18 jul. 2014.

${ }^{31}$ BRASIL. Tribunal Regional do Trabalho da $15^{\text {a }}$ Região. Recurso Ordinário. 0163500-21.2005. 5.15.0102. 2 2âmara (1 ${ }^{\mathrm{a}}$ Turma) do Tribunal Regional do Trabalho da $15^{\text {a }}$ Região do Estado de São Paulo, Campinas,SP, Relatora Mariane Khayat, publicado em 06.02.2009. Disponível em: <http://www.trt15.jus.br/portal/portal/trt15/home>. Acesso em: 10 ago. 2014.

32 BRASIL. Tribunal Regional do Trabalho da $15^{\text {a }}$ Região. Recurso Ordinário. 0163500-21.2005. 5.15.0102. $2^{\mathrm{a}}$ Câmara (1 ${ }^{\mathrm{a}}$ Turma) do Tribunal Regional do Trabalho da $15^{\mathrm{a}}$ Região do Estado de São Paulo, Campinas,SP, Relatora Mariane Khayat, publicado em 06.02.2009. Disponível em: <http://www.trt15.jus.br/portal/portal/trt15/home>. Acesso em: 10 ago. 2014.

33 BRASIL. Tribunal Regional do Trabalho da $15^{\text {a }}$ Região. Recurso Ordinário. 0063000-58.2009. 5.15.0052, 4 $4^{\mathrm{a}}$ Câmara (2 ${ }^{\mathrm{a}}$ Turma) do Tribunal Regional do Trabalho da $15^{\mathrm{a}}$ Região do Estado de São Paulo, Campinas, SP. Relator Luiz José Dezena da Silva, publicado em 13.07.2012. Disponível em: <http://www.trt15.jus.br/portal/portal/trt15/ home>. Acesso em: 10 jul. 2014.

${ }^{34}$ Art. $1^{\circ}$ A República Federativa do Brasil, formada pela união indissolúvel dos Estados e Municípios e do Distrito Federal, constitui-se em Estado Democrático de Direito e tem como fundamentos: III - a dignidade da pessoa humana. (BRASIL. Constituição da República Federativa do Brasil de 1988. Disponível em: <https://www.planalto.gov.br/ccivil_03/ Constituicao/ConstituicaoCompilado.htm $>$. Acesso em: 03 set. 2014)

35 Art. $3^{\circ}$ Constituem objetivos fundamentais da República Federativa do Brasil: I - construir uma sociedade livre, justa e solidária; [...] IV promover o bem de todos, sem preconceitos de origem, raça, sexo, cor, idade e quaisquer outras formas de discriminação. ( BRASIL. Constituição da República Federativa do Brasil de 1988. Disponível em: <https:// www.planalto.gov.br/ccivil_03/Constituicao/ConstituicaoCompilado. $\mathrm{htm}>$. Acesso em: 03 ago. 2014).

${ }^{36}$ Art. $5^{\text {o }}$ Todos são iguais perante a lei, sem distinção de qualquer natureza, garantindo-se aos brasileiros e aos estrangeiros residentes no País a inviolabilidade do direito à vida, à liberdade, à igualdade, à segurança e à propriedade [...] ( BRASIL. Constituição da República Federativa do Brasil de 1988. Disponível em: <https://www.planalto.gov.br/ccivil 03/ Constituicao/ConstituicaoCompilado. $\mathrm{htm}>$.Acesso em: 03 ago.2014).

37 ORGANIZAĈ̃O INTERNACIONAL DO TRABALHO (OIT). Convenção Internacional $n^{\circ} 111$, de 04 de junho de 1958, sobre Discriminação em Matéria de Emprego e Ocupação. Disponível em: <http://www.oitbrasil.org.br/node/472\#_ftn1>. Acesso em: 10 jul. 2014. 